\title{
Biological Synthesis of Gold Nanostructures Using the Extract of Trichoderma koningii
}

\author{
I. Maliszewska*, Ł. Aniszkiewicz And Z. SAdowski \\ Department of Chemistry, Technical University of Wrocław,Wybrzeże Wyspiańskiego 27, 50-370 Wrocław, Poland \\ The fungus-mediated synthesis of gold nanoparticles with various shapes and sizes is reported. Shape and \\ size of the products may be controlled using different concentrations of $\mathrm{HAuCl}_{4}$.
}

PACS numbers: 87.17.Uv

\section{Introduction}

The gold nanoparticles exhibit unique optical, thermal, chemical and physical properties [1, 2]. Subsequently, strong interest is shown in the development of processes for such synthesis of nanogold particles with various shapes and sizes [3]. Most of the current methods of preparation are based on the use of toxic chemicals, including strong reducing agents, organic solvents or surfactants. Developments of clean and eco-friendly procedures are important steps in the field of nanotechnology, as many organisms have the ability to produce such inorganic nanostructures and metal nanoparticles [4]. The examples include the formation of iron oxides using bacteria [5], silica deposition in diatoms [6] and the formation of various metal nanoparticles (CdS, magnetic, silver, gold, palladium) using bacteria, fungi or plants [7-10].

Here, we report the use of a filamentous fungus (Trichoderma koningii) in the synthesis of extracellular gold nanoparticles. We show that it is possible to develop a biological protocol for the shape and size controlled synthesis of gold nanoparticles, using the above mentioned fungal based biological system.

\section{Experimental section}

\subsection{Materials}

All chemical agents including chloroauric acid $\left(\mathrm{HAuCl}_{4}\right)$ were obtained from POCH (Poland)

\subsection{Synthesis of gold nanoparticles}

The T. koningii strain isolated from soil was studied. The inoculated fungi were prepared in Petri dishes at room temperature using a $2 \%$ malt extract combined with $0.5 \%$ of yeast. The fungal biomass used for the biosynthetic experiments was grown aerobically in a liquid medium containing (g/l): $\mathrm{KH}_{2} \mathrm{PO}_{4} 7.0 ; \mathrm{K}_{2} \mathrm{HPO}_{4} 2.0$;

\footnotetext{
* corresponding author; e-mail:

irena.helena.maliszewska@pwr.wroc.pl
}

$\mathrm{MgSO}_{4} \cdot 7 \mathrm{H}_{2} \mathrm{O} 0.1 ;\left(\mathrm{NH}_{4}\right)_{2} \mathrm{SO}_{4} 1.0$; yeast extract 0.6 ; glucose 20.0. The Erlenmeyer flasks were inoculated with spores and incubated at $25^{\circ} \mathrm{C}$ shaking at $150 \mathrm{rpm}$ for $120 \mathrm{~h}$. After the incubation the biomass was filtered (Whatman filter paper No. 1), and then extensively washed with distilled water to remove any medium components. Fresh and clean biomass was incorporated into the Erlenmeyer flasks, containing $100 \mathrm{ml}$ of Milli-Q deionized water. The flasks were agitated at $25^{\circ} \mathrm{C}$ shaking at $150 \mathrm{rpm}$ for $72 \mathrm{~h}$. Later the biomass was filtered again (Whatman filter paper No. 1), and the cell-free filtrate was used in the next experiments. Chloroauric acid at final concentrations of: $0.18,0.37,0.74,1.50$ or $2.21 \mathrm{mM}$ was added to the cell-free filtrate and agitated at $25^{\circ} \mathrm{C}$ in dark. The control (without the gold ions) was also run along with the experimental flasks. To verify the reduction of gold ions, samples of $1 \mathrm{ml}$ were withdrawn at different times and scanned in the range of $200-800 \mathrm{~nm}$ in a UV-visible spectrophotometer (HELIOS $\lambda$, ThermoElectron Corp.).

Parallel experiments were performed with heat-denaturated cell-free filtrate in the nanoparticles synthesis. The denaturation was achieved by heating the filtrate at $80^{\circ} \mathrm{C}$ for $30 \mathrm{~min}$.

\subsection{Electron microscopy (TEM)}

The transmission electron microscopy (TEM) samples of gold nanoparticles synthesized using a cell filtrate were prepared by placing $2 \mu \mathrm{l}$ of the final product solution onto carbon-coated copper grids and allowing the solvent to evaporate in air.

\section{Results and discussion}

The fungal biomass after incubation for $72 \mathrm{~h}$ with deionized water was separated by filtration, and the cell-free filtrate chloroauric acid was added. The condition of the reaction was based on the primary variable which was the concentration of $\mathrm{HAuCl}_{4}$ used in our experiments.

The gold nanoparticle morphologies generated using the fungal cell-free filtrate were monitored by the changes in the UV-Vis spectra of nanoparticles (Fig. 1). It is well 
known that the optical properties of the metal nanoparticles are strongly dependent on their size and shape. According to the Mie theory (after Gustav Mie who made the most considerable contribution to the theoretical interpretation of this phenomenon) the small gold nanoparticles exhibit only a single surface plasmon resonance (SPR) absorption, whereas the anisotropic particles of the same metal have two or three SPR bands depending of their shapes. As shown in Fig. 1, the UV-Vis spectra recorded from solutions in which the concentrations of $\mathrm{HAuCl}_{4}$ were at the range of $0.18-0.74 \mathrm{mM}$ and $2.21 \mathrm{mM}$, showed the appearance of a single and strong SPR band absorption peak centered at about $534 \mathrm{~nm}$, which indicated that these particles are isotropic in shape and uniform in size. Although, when the concentration of $\mathrm{HAuCl}_{4}$ was at $1.5 \mathrm{mM}$ the two distinct absorptions centering at $566 \mathrm{~nm}$ and $866 \mathrm{~nm}$ (data not shown), were observed.

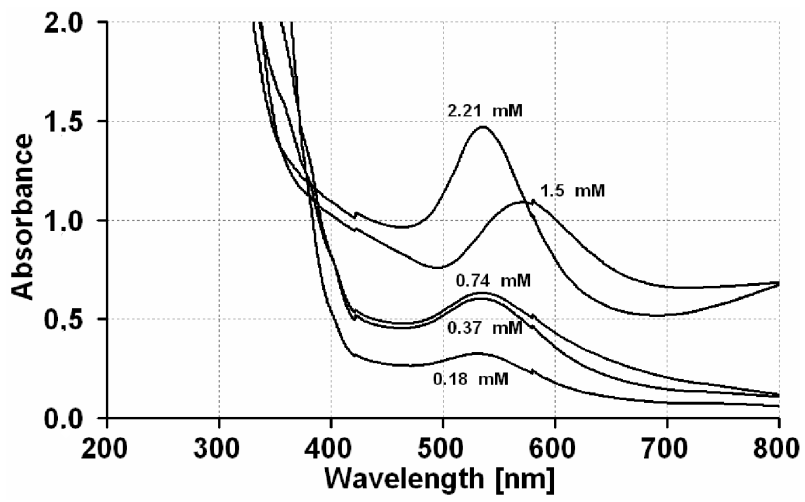

Fig. 1. UV-Vis spectra of gold nanoparticle solution synthesized at various concentrations of $\mathrm{HAuCl}_{4}$.

Apart from this, the absorption peak at $210 \mathrm{~nm}$ was assigned to the strong absorption of the peptide bonds in the filtrate. The absorption at $280 \mathrm{~nm}$ indicated the presence of tryptophan, tyrosine and/or phenylalanine residues in the protein (data not shown). This observation indicates the release of the protein into the cell-free filtrate suggesting a possible mechanism for the reduction of gold ions present in the solution.

The gold of nanostructures synthesized in the fungal filtrate were further characterized by TEM. A representative TEM image of gold nanoparticles produced by the cell-free filtrate with $1.5 \mathrm{mM}$ of $\mathrm{HAuCl}_{4}$ is shown in Fig. 2. Gold nanoparticles were formed in several different shapes, ranging from polydisperse small spheres to large polygons (triangles and hexagons). The lateral sizes of the triangles were in the range of 30-40 nm and the thickness was approximately $5-10 \mathrm{~nm}$.

It is clear that the T. konigii releases reducing agents into the solution which are responsible for the formation of gold nanoparticles. The UV-Vis and fluorescence measurements of the cell-free filtrate clearly showed the presence of protein in the solution (data not shown). However, the cellular mechanism leading to the biosyn-

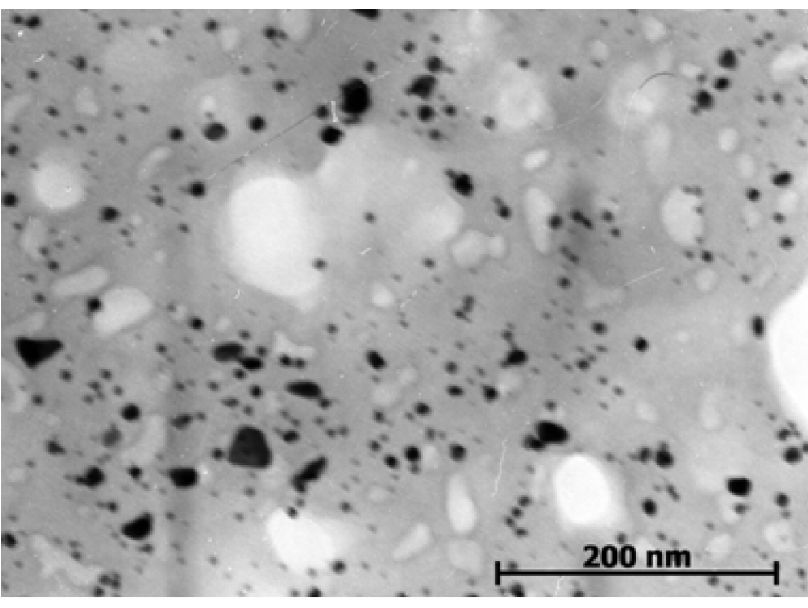

Fig. 2. Transmission electron micrograph of gold nanoparticles synthesized by cell-free filtrate of T. koningii.

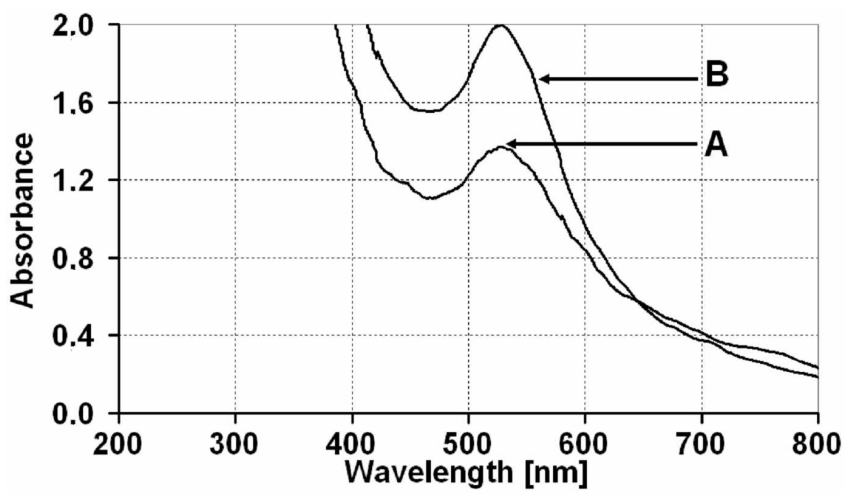

Fig. 3. UV-Vis spectra of gold nanoparticle solution synthesized by (A) cell-free filtrate and (B) heat-denaturated protein in the filtrate.

thesis of gold nanoparticles is not yet fully understood. Previous studies indicated that glucose oxidase [11] or nicotinamide adenine dinucleotide dependent (NADH-dependent) reductase enzymes [12] are important factors in the biosynthesis of gold nanoparticles. A control experiment using the denaturated protein in the cell-free filtrate (Fig. 3) showed an intense peak at around $530 \mathrm{~nm}$ appearing within $24 \mathrm{~h}$, indicating that the denaturated protein also produced nanogold. The ability of the heat-denaturated protein in the cell-free filtrate to synthesize gold nanocrystals, indicated that the native three-dimensional structure of protein was not essential in the process. The increased rate of production of $\mathrm{Au}^{0}$ by the denaturated protein indicated a rapid reduction of $\mathrm{Au}^{3+}$ to $\mathrm{Au}^{0}$ due to the exposed functional groups. One of the functional groups that could be important in reduction of $\mathrm{Au}^{3+}$ is the thiol group (-SH), present in the side chain of cysteine. It is known that the $-\mathrm{SH}$ groups react with $\mathrm{AuCl}_{4}^{-}$to form $\mathrm{Au}-\mathrm{S}$ bonds, thus most likely. Probably in our experiments the free thiol groups present in pro- 
teins were responsible for the reduction of $\mathrm{Au}^{3+}$ to $\mathrm{Au}^{0}$. Our results are in agreement with the previous studies of Rangnekar et al. [13]. Their observations suggested that the presence of free and exposed $\mathrm{S}-\mathrm{H}$ groups in $\alpha$-amylase is essential in the reduction of gold ions. However, further experiments should be performed to elucidate the mechanisms involved in the biosynthesis of gold nanoparticles by T. koningii.

\section{References}

[1] M.C. Daniel, D. Astruc, Chem. Rev. 104, 293 (2004).

[2] S. Eustis, M.A. El-Sayed, Chem. Soc. Rev. 35, 209 (2006).

[3] S. Gua, E. Wang, Anal. Chim. Acta 598, 181 (2007).

[4] M. Gerinke, A. Pinkles, Hydrometallurgy 83, 132 (2006).

[5] Q.J. Crookes-Goodson, J.M. Slocik, R.R. Naik, Chem. Soc. Rev. 37, 2403 (2008).
[6] N. Kroger, R. Deutzmann, M. Sumper, Science 286, 1129 (1999)

[7] A. Ahmad, P. Mucherjae, D. Mandal, S. Senepati, M.I. Khan, M. Sastry, J. Am. Chem. Soc. 124, 12108 (2002).

[8] H. Spring, K.H. Schleifer, Syst. Appl. Microbiol. 18, 147 (1995).

[9] E. Dujardin, S. Hann, Adv. Mater. 14, 775 (2002).

[10] M. Sastry, A. Ahmad, M.I. Khan, R. Kumar, Curr. Sci. 85, 162 (2003).

[11] J. Xie, J.Y. Lee, D.I.C. Wang, Y.P. Ting, J. Phys. Chem. C 111, 16858 (2007).

[12] P. Mukherjee, S. Senapati, D. Mandal, A. Ahmad, M.I. Khan, R. Kumar, M. Sastry, Chem. Biol. Chem. 5, $461(2002)$.

[13] A. Rangnekar, T.K. Sarma, A.K. Singh, J. Deka, A. Ramesh, A. Chattopadhyay, Langmuir 23, 5700 (2007). 